\title{
Impact of Labor Mobility on Comparative Advantage of Manufacturing Industries in China: Empirical Analysis
}

\author{
Shuang Zhao \\ School of Business, Nanjing Normal University, Nanjing, China \\ Email address: \\ zhaos1992@126.com \\ To cite this article: \\ Shuang Zhao. Impact of Labor Mobility on Comparative Advantage of Manufacturing Industries in China: Empirical Analysis. International \\ Journal of Business and Economics Research. Vol. 7, No. 2, 2018, pp. 25-30. doi: 10.11648/j.ijber.20180702.11
}

Received: March 7, 2018; Accepted: March 28, 2018; Published: April 28, 2018

\begin{abstract}
This paper studies the impact of labor mobility on comparative advantage of China's manufacturing industries. Labor mobility refers to labor movement across regions and industries. Comparative advantage refers to better product performance in international trade in aspect of quality and price, and it can be reflected directly in export values. Industries with comparative advantage have more benefits in international trade. Firstly, this paper reviews literatures that focus on impact of labor market on comparative advantage. Secondly, this paper illustrates the mechanism of how labor mobility has impact on comparative advantage. Thirdly, the empirical analysis tests this mechanism through mixed OLS (Ordinary Least Square) regression and one-way FEM (Fixed Effects Model), using panel data of China subdivision export. The results of empirical analysis support the mechanism. Lastly, this paper reaches a conclusion that higher labor mobility has positive impact on comparative advantage in highly volatile industries, due to the fact those industries in higher labor mobility regions have stronger ability and lower cost to adjust production scale when confronted with economic shocks.
\end{abstract}

Keywords: Labor Mobility, Comparative Advantage, Industry Volatility

\section{Introduction}

Comparative advantage refers to advantages that exporters have in aspect of product quality and product price compared with others. Generally, export value of a region or an industry can reflect its comparative advantage. After the reform and opening-up, attracted by rapid economic growth in coastal regions, labor force in China has become massively mobile across regions. Massive labor movement across regions continues to influence different aspects of economic development of China. The labor movement towards coastal regions brought down labor cost in manufacturing industries and enormously enhanced export trade. This phenomenon implies a possibility that labor mobility can have impact on comparative advantage of manufacturing industries. The purpose of this paper is to study the positive impact of labor mobility on comparative advantage empirically.

\section{Literature Review}

Labor market can have influence on comparative advantages of a country. Researchers studied the impact of legal systems in labor market on international trade [1]. After adding a variable that represents legal systems into the Heckscher-Ohlin model in empirical analysis, the result shows that implementation of the minimum wage system can enhance comparative advantage of labor-intensive industries. Researchers studied the relationship between legal system in labor market and international trade in China and reached similar conclusions: the implementation of Labor Contract Law can influence employment behavior of exporters [2]. Besides legal systems, flexibility of labor market institutions also has impact on comparative advantage. The more flexible the labor market institutions are in a country, the more advantageous the country is in volatile industries [3]. These literatures show the relationship between labor market and comparative advantage.

In literatures that focus on relationship between labor market and international trade [4-15], labor mobility has not received adequate attention. This paper intends to approach this question through empirical analysis. This paper illustrates the mechanism of how labor mobility has impact on comparative advantage. And test this mechanism through empirical analysis. 


\section{Illustration of the Mechanism}

\subsection{The Concept of Labor Mobility}

Labor mobility refers to labor movement across regions and industries, and this paper focuses on regional movement of labor. According to Laws of Migration [16], the most fundamental driver of labor mobility is economic factors. And many factors can influence the level of labor mobility as below.

\subsubsection{Quantity of Labor Movement}

The greater the quantity of labor movement is, the higher the level of labor mobility the region has. And the quantity is positively related to the gap of economic development between in-flow and out-flow regions. The greater the gap is, the greater the quantity of labor movement is.

\subsubsection{Cost of Labor Movement}

The higher the cost of labor movement is, the lower the level of labor mobility the region has. From the perspective of manufacturers, the cost of labor movement includes matching cost, hiring cost, and firing cost in labor market. From the perspective of labor force, the cost of labor movement includes cost of searching for a new job, cost of regaining professional skills, and cost of immigration across regions. In China, the Household Registration System is a major obstacle for labor movement, because it increases the cost of labor movement, and decreases the labor mobility.

\subsubsection{Capability of Labor}

The stronger the capability that labor has in order to move across regions, the higher the level of labor mobility the region has. The capability of labor includes general skills (ability to search for new jobs, communicating ability, interviewing skills, etc.), professional skills, and education level. Workers with stronger capabilities will encounter less obstacles and more opportunities in labor movement.

\subsection{The Concept of Comparative Advantage}

The concept of comparative advantage was first brought up in 1817 [17]. Back in that times, comparative advantage meant that one country was able to produce certain goods at lower cost than other countries. By now, the concept of comparative advantage has broken through the old concept, and means that producers, industries, and countries are able to manufacture goods of better quality, lower cost, and more suitable to emerging demands in world economy.

\subsection{Mechanism}

Firstly, manufacturing industries have to face economic and non-economic shocks that exist in domestic and foreign economies, including endogenous economic cycles, external economic shocks, and worldwide accidental events. These shocks constitute the developing environment for manufacturers and have impact on the demand for quantity, quality and other aspects of products. Due to different characteristics of industries, these shocks will lead to different volatility levels among industries. Industries that are more sensitive to shocks will be more volatile compared to less sensitive industries.

Secondly, different regions have different labor mobility. In regions with higher labor mobility, the matching efficiency between labor force and manufacturers is higher and the matching cost is lower in labor market.

Thirdly, when shocks come, two basic changes of demands emerge that manufacturers have to deal with quickly to remain competitive. The first change is demand of quantity, the second is demand of quality. For industries located in higher labor mobility regions, they are able to adjust their employment strategies quicker, due to higher matching efficiency. When there emerges a rapid increase or decrease in demand quantity, these industries can adjust employment strategies to change the number of their labor force in order to adjust the output quickly; When there emerge requirement changes in product quality, these industries can also adjust employment strategies to change the skill level of their labor force to deal with it quickly. Industries that can quickly adjust employment strategies have lower costs in the face of shocks. As China becomes more closely related to GVCs (Global Value Chains), industries in China are now facing a higher frequency of external and endogenous shocks. Industries in higher labor mobility regions have lower adjusting cost, therefore have lower producing cost. Lower producing cost is a key determinant of comparative advantages. That is, higher labor mobility enhances comparative advantages, and this is more significant for highly volatile industries.

In short, for more volatile industries, industries in higher labor mobility regions have comparative advantages.

\section{Empirical Analysis}

\subsection{Data Source}

This paper uses panel data of 30 provinces and cities in China except Tibet (data of Tibet is seriously missing) from 2013 to 2015. According to the Industry Classification of National Economy (2011) in China, manufacturing industries are classified into 29 subdivisions. Raw data are from China Industrial Statistics Yearbook, China Labor Statistics Yearbook, the 6th National Census Report, and National Bureau of Statistics of China.

\subsection{Baseline Model}

This paper adopts the same baseline model of a study on the impact of institutional environment on comparative advantage [18]. The study added interaction between institutional environment and sensitivity to institutional environment of different product into baseline model. According to the mechanism above, this paper takes labor mobility as major variable, and brings it into the model in the form of interaction with industry volatility. The model is designed to test whether labor mobility have an impact on comparative advantage.

The baseline model is: 


$$
E_{s r}=\alpha_{r}+\beta_{v m}\left(\operatorname{Vol}_{s} \cdot \mathrm{Mob}_{r}\right)+\beta_{n} \cdot \text { Control }_{n}+\varepsilon_{s r}
$$

$E_{s r}$ stands for export of $s$ industry in $r$ region, and it measures comparative advantage. $\alpha_{r}$ stands for regional fixed effect. $V o l_{s}$ stands for industry volatility. $M o b_{r}$ stands for labor mobility in $r$ region. Control $_{n}$ stands for a matrix of control variables that affect the comparative advantage. $\varepsilon_{s r}$ stands for random disturbance term.

\subsection{Control Variables}

Control variables are factors besides major variables that also have impact on comparative advantage in domestic economy, this paper selects following factors as control variables: (1) Factor endowments. According to Heckscher-Olin theory, factor endowment of a country (region) has a significant impact on comparative advantage. This paper adds physical resource endowment, natural resource endowment, and human resource endowment as control variables. (2) Economic development. Developed regions are generally more advanced in technology and probably occupy comparative advantage. Therefore, this paper adds economic development into control variables.

\subsection{Measurements}

\subsubsection{Comparative Advantage}

This paper adopts export value as the measurement of comparative advantage. Take the logarithm of export volume and denote it as $\log E_{s r}$.

\subsubsection{Labor Mobility}

This paper uses "the number of residents living in their own township, town and street, the number of people living in other townships, towns and streets, and residents leaving the registered residence for more than half a year" as the measurement of migrant population, denoted as $M P_{r}$. The total population of a region is denoted as $T P_{r}$. And labor mobility of a region is:

$$
M o b_{r}=M P_{r} / T P_{r}
$$

\subsubsection{Industry Volatility}

This paper uses sales fluctuation of industries as measurement of industry volatility. First calculate the absolute value of standard deviation of increase or decrease, then average the absolute value among years and denote it as $\mathrm{Vol}_{s}$.

\subsubsection{Physical Resource Endowment}

This paper uses physical capital stock per worker as the measurement of physical resource endowment. Average the physical capital stock per worker among years, then take logarithm and denote it as $\log K_{s}$.

\subsubsection{Human Resource Endowment}

This paper uses weighted average education level as measurement of human resource endowment in different industries and regions. Take logarithm of it and denote it as $\log S_{s}, \log S_{r}$

\subsubsection{Natural Resource Endowment}

This paper uses output value per capita of mining industry of a region as the measurement of natural resource endowment. Take logarithm and denote it as $\log K_{r}$.

\subsubsection{Economic Development}

GDP per capita is used as measurement of economic development of different industries and regions. First average GDP per capita among years to eliminate time effects, then take logarithm, and denote it as $\log G D P, \log G D P_{r}$.

\subsection{Empirical Tests}

\subsubsection{Mixed OLS Regression}

The basic model including all control variables and interaction items is:

$$
\begin{aligned}
& \log E_{s r}= \\
& \beta_{0}+\beta_{v m}\left(V o l_{s} \cdot M o b_{r}\right)+\beta_{k m}\left(\log K_{s} \cdot M o b_{r}\right)+ \\
& \beta_{k \mathrm{k}}\left(\log K_{s} \cdot \log K_{r}\right)+\beta_{s s}\left(\log S_{s} \cdot \log S_{r}\right)+ \\
& \beta_{g r s}\left(\log G D P_{r} \cdot \log G D P_{s}\right)+\beta_{g r k s}\left(\log G D P_{r} \cdot \log K_{s}\right)+ \\
& \beta_{g r s s}\left(\log G D P_{r} \cdot \log S_{s}\right)+\beta_{g r k r}\left(\log G D P_{s} \cdot \log K_{r}\right) \\
& \beta_{g s s r}\left(\log G D P_{s} \cdot \log S_{r}\right)+\varepsilon_{s r}
\end{aligned}
$$

First, test the basic model through mixed OLS regression to examine the model preliminarily. Results are showed in Table 1. Result (1) is the model with no control variables, the explaining variable only contains the interaction between labor mobility and industry volatility. The result shows the explanatory ability of the model is weak. Therefore, it is necessary to add control variables, and check whether the control variables should be included. Results (2) - (9) are models with different control variables. Results show that when control variables are added, the goodness of fitness $\left(R^{2}\right)$ does not decrease, and the overall trend is upward. The control variables can strengthen the explanatory ability of the model. Result (9) is the model including all control variables and interaction items. Most variables pass significance test at $1 \%$ level, and the results preliminarily explains the impact of explanatory variables on comparative advantage.

\subsubsection{One-Way FEM}

Hausmann test shows that panel data has fixed effect. In this situation, using OLS regression will cause incorrect and biased results. Therefore, this paper carries out one-way FEM regression of the basic model to obtain accurate and unbiased results. Results are showed in Table 2. There are four variables that have no significant influence on comparative advantage. After deleting these four variables, the modified model become:

$$
\begin{aligned}
& \log E_{s r}= \\
& \beta_{0}+\beta_{v m}\left(V o l_{s} \cdot M o b_{r}\right)+\beta_{k m}\left(\log K_{s} \cdot M o b_{r}\right)+ \\
& \beta_{k \mathrm{k}}\left(\log K_{s} \cdot \log K_{r}\right)+\beta_{s s}\left(\log S_{s} \cdot \log S_{r}\right)+ \\
& \beta_{g r s}\left(\log G D P_{r} \cdot \log G D P_{s}\right)+\mathcal{E}_{s r}
\end{aligned}
$$

The results of modified model are showed in Table 3. 


\section{Results}

As can be seen from Table 3: (1) $F$ value shows that there is significant individual effect in the panel data, and it is not appropriate to use mixed OLS regression. It is propriate to adopt the method of one-way FEM model. (2) Rho value shows that all variations of comparative advantage are related to regional differences. (3) The coefficient of interaction between labor mobility and industry volatility passes significance test at $1 \%$ level. And the coefficient is positive. It indicates that the combined effect of labor mobility and industry volatility has significantly positive impact on comparative advantage. (4) The coefficient of interaction between labor mobility and physical capital endowment passes significance test at $1 \%$ level, and the coefficient is negative. It indicates that the combined effect of labor mobility and physical resource endowment has significantly negative impact on comparative advantage. (5) The interaction between physical resource endowment and natural resource endowment does not pass the significance level test. It shows that the impact of this variable on comparative advantage is not significant. (6) The interaction of regional human resource endowment and industry human resource endowment is significant at $1 \%$ level, and the coefficient is positive. It indicates that if other variables remaining the same, the higher the level of human resource endowment is, the stronger the comparative advantage will be. (7) The interaction of regional GDP per capita and industry GDP per capita is significant at $1 \%$ level. Contrary to common sense, and the coefficient is negative. This shows a negative impact of economic development on comparative advantage. The reason is that in this paper, 29 subdivisions are not classified into categories of labor-intensive, capital-intensive, and knowledge-intensive industries. In China, the export of labor-intensive products is enormous and still occupies the major proportion of exports. But in developed regions of China, capital-intensive and knowledge-intensive products are major export products. As a result, the total trade value of developed regions may be less in quantity than labor-intensive products of less developed regions. This situation causes a reverse relation of economic development and comparative advantage.

Table 1. Results of mixed OLS regression.

\begin{tabular}{|c|c|c|c|c|c|c|c|c|c|}
\hline Variable & (1) & (2) & (3) & (4) & (5) & (6) & (7) & (8) & (9) \\
\hline Vols $\cdot$ Mobr & $4.157 * * *$ & $2.691 * * *$ & $2.764 * * *$ & $3.302 * * *$ & $3.385 * * *$ & $3.327 * * *$ & $3.324 * * *$ & $3.335 * * *$ & $3.379 * * *$ \\
\hline $\log \mathrm{Ks} \cdot \mathrm{Mobr}$ & & $0.645 * * *$ & $0.742 * * *$ & -0.271 & $-0.606 * *$ & $-0.567 * *$ & $-0.531 *$ & $-0.532 *$ & $-0.488 * * *$ \\
\hline $\log \mathrm{Ks} \cdot \log \mathrm{Kr}$ & & & $-1.503 * * *$ & $-1.685 * * *$ & $-1.520 * * *$ & $-1.486 * * *$ & $-1.433 * * *$ & $-1.432 * * *$ & $-1.311 * * *$ \\
\hline $\log S s \cdot \log S r$ & & & & $4.122 * * *$ & $3.554 * * *$ & $3.384 * * *$ & $3.144 * * *$ & $3.144 * * *$ & $3.087 * * *$ \\
\hline $\log G D P r \cdot \log G D P s$ & & & & & $0.323 * * *$ & $0.337 * * *$ & $0.351 * * *$ & $0.351 * * *$ & $0.318 * * *$ \\
\hline $\log \mathrm{GDPr} \cdot \log \mathrm{Ks}$ & & & & & & $0.255 * * *$ & $0.566 * * *$ & $0.561 * * *$ & $1.507 * * *$ \\
\hline $\log \mathrm{GDPr} \cdot \log \mathrm{Ss}$ & & & & & & & $-0.599 * *$ & $-0.583 * *$ & $-1.574 * * *$ \\
\hline $\log$ GDPs $\cdot \log S r$ & & & & & & & & & $-0.862 * * *$ \\
\hline Constant & $1.021 * * *$ & $0.869 * * *$ & $1.184 * * *$ & $-2.716 * * *$ & $-2.493 * * *$ & $-2.577 * * *$ & $-2.248 * * *$ & $-2.264 * * *$ & -0.684 \\
\hline Observation & 870 & 870 & 870 & 870 & 870 & 870 & 870 & 870 & 870 \\
\hline R-squared & 0.025 & 0.037 & 0.133 & 0.164 & 0.175 & 0.182 & 0.187 & 0.187 & 0.202 \\
\hline
\end{tabular}

Notes: *, **, *** respectively represents the variable passes significance test at level of 10\%, 5\%, $1 \%$.

Table 2. Results of one-way FEM.

\begin{tabular}{|c|c|c|c|c|}
\hline Variable & C. V. & Std. error & $\mathbf{t}$ & $\mathbf{P}>|\mathbf{t}|$ \\
\hline Vols·Mobr & 2.9238 & 0.6596 & 4.4300 & 0.0000 \\
\hline $\log \mathrm{Ks} \cdot \mathrm{Mobr}$ & -1.9865 & 0.5666 & -3.5100 & 0.0000 \\
\hline $\log \mathrm{Ks} \cdot \log \mathrm{Kr}$ & 0.7880 & 0.4737 & 1.6600 & 0.0970 \\
\hline $\operatorname{logSs} \cdot \log \mathrm{Sr}$ & 3.9693 & 0.7551 & 5.2600 & 0.0000 \\
\hline $\log \mathrm{GDPr} \cdot \log \mathrm{GDPs}$ & -1.0736 & 0.2603 & -4.1200 & 0.0000 \\
\hline $\log \mathrm{GDPr} \cdot \log \mathrm{Ks}$ & 0.1659 & 0.2838 & 0.5800 & 0.5590 \\
\hline $\log G D P r \cdot \log S s$ & -0.0300 & 0.3635 & -0.0800 & 0.9340 \\
\hline $\log$ GDPs $\cdot \log S r$ & -0.0007 & 0.2022 & 0.0000 & 0.9970 \\
\hline Constant & -1.3803 & 0.7509 & -1.8400 & 0.0660 \\
\hline Sigma $u=1.0683$ & & \multicolumn{3}{|c|}{ Rho $=0.7721$} \\
\hline Sigma e $=0.5803$ & & \multicolumn{3}{|c|}{ R-Square (within) $=0.1054$} \\
\hline$F(9,831)=10.88$ & & \multicolumn{3}{|c|}{ Prob $>F=0.0000$} \\
\hline$F(29,831)=29.35$ & & \multicolumn{3}{|c|}{ Prob $>F=0.0000$} \\
\hline
\end{tabular}

Table 3. Results of modified one-way FEM.

\begin{tabular}{lllll}
\hline Variable & C. V. & Std. error & t & P>|t| \\
\hline Vols $\cdot$ Mobr & 2.9126 & 0.6589 & 4.4200 & 0.0000 \\
$\operatorname{logKs} \cdot$ Mobr & -1.9823 & 0.5665 & -3.5000 & 0.0000 \\
$\operatorname{logKs} \cdot \operatorname{logKr}$ & 0.7470 & 0.4705 & 1.5900 & 0.1130 \\
$\operatorname{logSs} \cdot \operatorname{logSr}$ & 3.9447 & 0.7551 & 5.2200 & 0.0000 \\
$\log \mathrm{GDPr} \cdot \log G D P s$ & -1.0453 & 0.2598 & -4.0200 & 0.0000 \\
\hline
\end{tabular}




\begin{tabular}{lllll}
\hline Variable & C. V. & Std. error & t & P>|t $\mid$ \\
\hline Constant & -1.2290 & 0.6544 & -1.8800 & 0.0610 \\
Sigma $\mathrm{u}=1.0586$ & & Rho $=0.7721$ & \\
Sigma $\mathrm{e}=0.5804$ & & R-Square $($ within $)=0.1054$ & & \\
$\mathrm{~F}(5,835)=18.71$ & & Prob $>\mathrm{F}=0.0000$ & \\
$\mathrm{~F}(29,835)=31.17$ & & Prob $>\mathrm{F}=0.0000$ & & \\
\hline
\end{tabular}

\section{Conclusions}

Firstly, this paper illustrates the mechanism of how labor mobility has impact on comparative advantage through interaction with industry volatility. It is important for volatile industries to quickly shrink or expand production scale. In regions with higher labor mobility, the matching efficiency is higher, and the matching cost is lower in labor market. Therefore, industries in those regions are able to adjust to shocks at lower cost and then obtain comparative advantage. To test this mechanism empirically, this paper adopts one-way FEM. Empirical results support the mechanism in the third part and show that labor mobility has positive impact on comparative advantage.

Secondly, results show that interaction of labor mobility and industry capital density passes through the significance test and has negative impact on comparative advantage. This indicates that labor mobility also has impact on comparative advantage through industry capital resource endowment. Among industries with better capital resource, the improvement of labor mobility has a negative impact on comparative advantage. A possible explanation is that in regions with high labor mobility, labor-intensive industries are able to take full advantage of the lower matching costs in labor markets. This leads manufacturers to invest more in labor-intensive products and reduce the investment in capital-intensive products. This leads to low level R\&D investment in capital-intensive industries in these regions. In the long term, capital-intensive industries in this region will experience a weakening of comparative advantage.

Thirdly, the impact of labor mobility on comparative advantage is differentiated, due to different characteristics of regions and industries. For different regions, the mechanism of labor mobility is the same, but the impact level is different.

This paper illustrates the mechanism of labor mobility influencing comparative advantage and proves it through empirical tests. In China, a more flexible household registration system is needed to enhance labor mobility and create a more convenient environment for exporters to develop comparative advantages.

\section{References}

[1] Leamer E. Effort, Wages, and the International Division of Labor [J]. Journal of Political Economy, 1996, 107 (6), pp. 1127-1162.

[2] Zhiming Zhang, Riming Cui, Peng Dai. Open Trade, "Labor Contract Law" Implementation and Employment behavior of China's Manufacturing Industry from the Perspective of
Value-added Trade [J] International Trade issues, 2017. 04, pp. 153-165.

[3] Cuñat A, Melitz M J. Volatility, Labor Market Flexibility, and the Pattern of Comparative Advantage [J]. Journal of the European Economic Association, 2012, 10 (2), pp. 225-254.

[4] Saint-Paul, G. (1997): Is Labor Rigidity Harming Europe's Competitiveness? The Effect of Job Protection on the Pattern of Trade and Welfare, European Economic Review, 41, pp. 499-506.

[5] Belloc M. Do Labor Market Institutions Affect International Comparative Advantage? An Empirical Investigation [J]. Department of Economics University of Siena, 2004.

[6] Helpman E. Labor Market Rigidities, Trade and Unemployment [J]. CEPR Discussion Papers, 2007, 77 (3):1100-1137.

[7] Helpman E. Labor Market Frictions as a Source of Comparative Advantage, with Implications for Unemployment and Inequality [J]. CEPR Discussion Papers, 2010.

[8] Dan Sheng, Kunwang Li, Yongjin Wang. Will Labor Mobility affect China's Regional Export Comparative advantage? An Empirical Study Based on the Industrial Segmentation Data of Provinces [J] World Economic Research, 2010, pp. 38-44 + 88 .

[9] Wooton, I., \& Haaland, J. I. (2007). Domestic labor market and foreign direct investment. Review of International Economics, 15 (3), 462-480.

[10] Redding, Stephen J., 2016. "Goods trade, factor mobility and welfare," Journal of International Economics, Elsevier, vol. $101(\mathrm{C})$, pages 148-167.

[11] Sebastian Galiani \& Gustavo Torrens, 2015. "The Political Economy of Trade and Labor Mobility in a Ricardian World," NBER Working Papers 21274, National Bureau of Economic Research, Inc.

[12] Ahsan, Rashad N. \& Chatterjee, Arpita, 2017. "Trade liberalization and intergenerational occupational mobility in urban India," Journal of International Economics, Elsevier, vol. 109 (C), pages 138-152.

[13] Almeida, Rita K. \& Poole, Jennifer P., 2017. "Trade and labor reallocation with heterogeneous enforcement of labor regulations," Journal of Development Economics, Elsevier, vol. $126(\mathrm{C})$, pages $154-166$.

[14] Gruen Adam \& Humus, David \& Olsen, Morten, 2015. "Trade Dynamics with Sector-specific Human Capital,"Journal of International Economics, Elsevier, vol. 97 (1), pages 126-147.

[15] David H. Autor \& David Dorn \& Gordon H. Hanson, 2016. "The China Shock: Learning from LaSbor-Market Adjustment to Large Changes in Trade," Annual Review of Economics, Annual Reviews, vol. 8 (1), pages 205-240, October.

[16] Corbett J. Ernest George Ravenstein, The Laws of Migration, 1885. [J]. CSISS Classics, 2003. 
[17] David Ricardo, the Works of David Ricardo, Vol. 1, On the Principles of Political Economy and Taxation, 2013 [M] The Commercial Press.
[18] Nunn N, Trefler Domestic Institutions as a Source of Comparative Advantage [M]// Handbook of International Economics. Elsevier B. V. 2014:263-315. 